\title{
Prognosis method for the energy demand of nearly-zero-energy buildings in different climates
}

\author{
U. Dietrich, F. Kiehl \& L. Stoica \\ REAP Research Group, HafenCity University Hamburg, Germany
}

\begin{abstract}
The European Directive 2010/31 claims that from 2020 on, only (nearly-) zeroenergy buildings may be built. To reach this, buildings have to be optimised energetically. The remaining energy demand has to be covered by renewable energy sources (PV, geothermal etc.) gained nearby, e.g. on site. Comparable predefined plot and office building sizes are investigated for all main climate zones around the globe. Each case study leads to a different energy demand, even though, the same energy generation systems have been applied being PV for power and geothermal energy for heating and cooling. The analysis investigates first, whether the limiting factor to reach a nearly-zero-energy building is in the PV or the geothermal system. Furthermore, in all case studies, the balance between the usable floor area and the surface area for renewable energy sources (roof surface area for PV, plot size for geothermal) is investigated. From this, the maximum numbers of storeys (which can be heated/ cooled) are given per location. Furthermore, consequences for the urban pattern of nearly-zero-energy buildings (like street width and building heights) are highlighted. The main outcome is a correlation between simulated data for the energy demand and climate data. If the architectural optimization follows the local climatic needs, linear equations appear between the simulated energy demand and the climate data for a scenario of optimised buildings. The equations for annual heating or cooling demand and heating or cooling degree hours are given.
\end{abstract}

Keywords: nearly-zero-energy building, renewable energy systems, thermal building simulation, different climates, office building, building design rules. 


\section{Introduction}

In the European Union, the building sector is responsible for $40 \%$ of the primary energy demand. The energy demand can be substantially reduced by an energy optimization of the building stock. The (nearly) zero-energy standard will be established in the frame of the EU by the Energy Performance of Buildings Directive (EPBD) 2010/31/EU starting in 2020. This affects both, new and retrofit buildings, and sets minimum requirements for the building envelope and the technical systems [1].

In a zero-energy building (ZEB), $100 \%$ of the primary energy consumption has to come from renewable energy sources. As claimed by the directive, these renewable energies have to be gained on site. That implies that building-integrated technologies for renewable energy can be used on the building façades, the roof surface, or the estate's ground. Other ZEB definitions allow compensating measures to balance lacking energy sources on site, i.e., renewable energy supply by district heating or cooling or even the national grid.

Up to now, two different concepts of energetically optimized buildings can be differentiated as follows: passive buildings and active ones. While the passive method ("passive house") deals with design principles to keep the building's energy losses as low as possible, an active approach ("solar house") tries to increase the energy gains with accordant technology (e.g. solar panels). Both principles individually are not sufficient to reach a ZEB; a well-designed synthesis of both is necessary. The sequence of priorities is as follows:

1. Reducing the building's primary energy demand to its minimum;

2. Cover the remaining energy demand with renewable energy gained on site;

3. Use compensating measures to bring the balance to zero, if necessary.

The building shape constitutes an important role for the passive optimization (e.g. for optimal daylight supply and minimal power demand for artificial light) as well as for the energy generation on façades or roof. Different locations in the world have diverse climatic preconditions and needs. In theory, this leads to very different design rules and architectural solutions. However, an "international style" office building that requires lots of heating and cooling at the perimeter just to maintain comfort is found worldwide. Adapted, climate responsive, traditional and modern optimised buildings have a much better energy performance. Therefore, efficient design approaches should not only adapt to climate but also to the specific culture and user behaviour.

\section{Methodology}

The overall aim of the investigation is to find out if and how far the realization of ZEBs is possible in different climatic zones. The analysed locations are chosen with the aim of covering most of the different climates. The local climate data for these locations is generated using the software Meteonorm 6.1 [2]. To simplify the task and to ensure the comparison among these locations, a standard office room is predefined. The exemplary room, used for all case studies, represents a typical 
standard office room in an office building. Theoretically, it can be placed and repeated on both building sides and additional floors can be added on top.

Simulations forecast the energy demand of the standard office room with its predefined configuration in all climates, using a transient simulation software. Assuming a specific energy system for all case studies, the primary energy demand, the options for renewable energy generation and the limiting factors for a ZEB are given at this stage. This scenario works as a baseline "international style" scenario.

This procedure is applied to the case studies again, with different sets of frame conditions, after the analysis of the specific climatic background, the local best practice examples as well as specific vernacular architecture. This includes the climatic parameters (e.g. temperature, solar radiation, wind direction and speed), the energy supply options, water availability (for evaporative cooling), the availability of local materials, as well as existing standards and laws. Out of this, specific design rules and strategies are derived.

The results show the relevant difference between the "international" and the "optimised" standard office room. The feasibility of the energy concept based on geothermal and solar energy (PV panels) is tested again, investigating the limiting factors for the realization of a ZEB, i.e., the possible number of storeys and the possibility of a reasonable urban pattern.

This leads to the main outcome of this paper, which lies in finding a possible correlation between simulated data for the energy demand and climate data of all locations. The proposed equations include data about annual heating and cooling demand, heating and cooling degree hours and electricity demand for lighting. Specific correlations of different climate zones are further investigated in order to narrow down the prognosis method for e.g. hot and humid, hot and dry or continental climate zones.

From the undertaken investigations, it becomes clear, that running all simulations is quite a complex job. For this reason, a new method is developed out of the previous investigations, based on its results. It functions as a simple prognosis method to determine the energy demand of ZEBs in different climatic areas in an early design stage.

\section{Assumptions and limitations}

\subsection{Choice of climates and locations}

Annual and monthly average temperatures as well as the amount of precipitation and its distribution pattern are important parameters to indicate climate. According to the climate classification system by Köppen and Geiger [3], there are: (A) equatorial climates, (B) arid climates, (C) warm temperate climates, (D) snow climates and (E) polar climates. In order to identify the climatic influences on architectural design, the following representative climates are regarded, to ensure a high diversity: 
(A) Hot and humid climates: El Salvador (San Salvador), Jakarta (Indonesia), Domingo (Dom. Rep), Singapore;

(B) Hot and dry climates: Delhi (India), Cairo (Egypt);

(C) Temperate climates: Hamburg (Germany), Mexico City (Mexico), Sydney (Australia), Santiago de Chile, Cape Town (South Africa), Madrid (Spain);

(D) Cold climates;

(E) Chicago (USA), Oslo (Norway).

\subsection{International style office room}

The study deals with a standard office room in a typical "international style" office building that could be found everywhere in the world. The "international style" building is characterized by fully glazed and sealed facades without paying any consideration to the local climate. To ensure indoor comfort, high-energy consumption is required for heating, cooling, lighting and ventilation.

To accurately compare "international style" office room and the optimized one, as well as to compare the different locations, the dimensions of $12 \mathrm{~m}$ width, $3.5 \mathrm{~m}$ height and $14 \mathrm{~m}$ depth define the office room (see fig. 1). These dimensions ensure a floor area of $168 \mathrm{~m}^{2}$ for 12 users. Such a unit with a building depth of $14 \mathrm{~m}$ is a very common assumption as it follows good daylight provision principles. The following characteristics are assumed just for the "international style" simulation:

- facade orientation to south/north;

- fully glazed facades, double pane window;

- internal shading system, $\mathrm{Fc}=0.75$;

- all internal constructions are light (skeleton);

- time of use 11 hours from 7 am to $6 \mathrm{pm}$;

- artificial light during time of use;

- mechanical ventilation during time of use;

- air change rate $21 / \mathrm{h}$ (summer) and $11 / \mathrm{h}$ with heat recovery (winter);

- 12 employees with their equipment (internal gains);

- cooling temperature set to $26^{\circ} \mathrm{C}$.
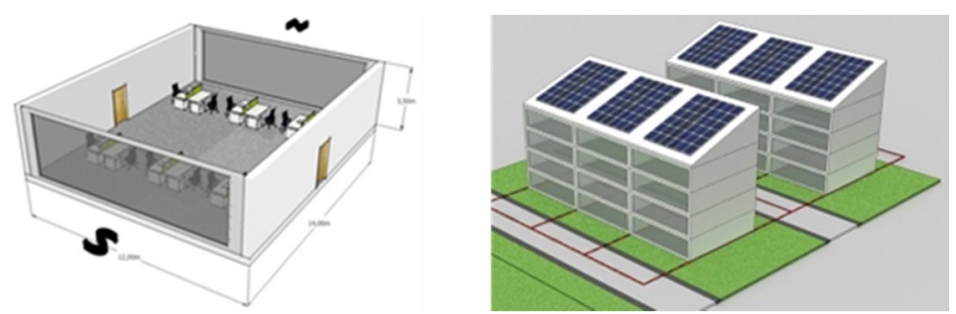

Figure 1: International style office room and its possible urban arrangement. 
To run the simulation for the optimised room, these parameters are modified according to the optimised local case studies. Examples of such varying parameters will be mentioned in section 5 .

\subsection{Energy systems for the production of renewable energy}

The energy concept for all case studies is based on a combination of geothermal and PV modules. The geothermal system provides heating and cooling with an electrically driven heat pump from borehole heat exchangers. PV modules generate the electricity, which is required to run the geothermal system and to provide ventilation and lighting.

The boreholes use the ground as a heat source in winter and as a heat sink in summer. The maximum depth of the boreholes is set to $100 \mathrm{~m}$, defined by the beginning of the mining law below $100 \mathrm{~m}$ in several countries. The boreholes have to be placed within a certain distance from each other. This distance is derived from the thumb rule, that one meter of borehole depth needs $1 \mathrm{~m}^{2}$ of estate, so that $10 \%$ of the borehole length defines the distance. One meter of borehole is able to deliver $600 \mathrm{Wh}$ of thermal energy per day [4].

For the heat pump, a COP (coefficient of performance) of 2.5 is assumed for cooling and a COP of 3.5 for heating. Due to the fact that the ground temperature does not have a strong influence on the COP, the assumed COP values are used for all the locations. For power, a primary energy factor of 3 is used for all the calculations. All these estimations are valid for the "international style" and the adapted scenario, in order to compare the architectural parameters, not the technical system.

The installation surface of the PV modules varies between all locations. Dependent on the sun path, in locations near the equator, PV modules are well positioned on a horizontal flat roof. Further away from the equator, the modules need a slope. This can be reached with a tilted roof or with elevated modules on the flat roof. In this case, spacing is necessary between the module rows, to prevent them from shading each another. As a result, only a part of the roof area can be used as an effective PV surface. In locations closer to the pole, vertical PV surfaces, e.g. in the façade, also perform well with minor reductions.

\subsection{Limitations in the use of active systems on site}

In general, the area of use producing demand of thermal energy and power competes with the size of the estate (for the geothermal system) and the size of the roof and the facades (for PV modules).

Using the geothermal system, to generate the heating and cooling demand, brings limitation to the street width and this is due to the space needed for boreholes in the ground. Also the use of PV modules to cover the power demand of the heat pump, artificial light and mechanical ventilation brings certain limitation distance between buildings, thus on the street width. The PV modules can be installed on either the building's roof or facades. As described previously, only a part of the roof area, can be covered with PV in an effective manner. A pitched roof can provide an optimal area for solar reception. However, this 
influences the building's architectural design and does not always fit. Especially in an urban scenario, the street width limits the PV potential in the northern locations.

In case of non-optimised, "international style" office buildings, the required estate for geothermal and required area and orientation of the PV modules, might result in such big street widths, that urban nearly-zero-energy quarters are only possible with a low number of storeys. However, in the adapted scenario, consequently more storeys and smaller distances between buildings are possible. For cases, where it is not possible to meet the target of using only on-site renewable energies in an urban scenario, the definition of a ZEBs used here requires compensating measures on the regional or national level.

\subsection{Climate analysis}

The climate is analysed with Climate Consultant 5.2 [5]. The parameters, which indicate the climatic needs, and thus the measures for climate responsive architecture, are:

- Solar radiation for the PV-harvest;

- Sun position for the placement of PV modules and the design of shading systems like overhangs and wing walls;

- Sky cover range for estimating the minimum size of windows for good daylight supply. As a thumb rule, when the sky type is defined as "cloudy" a minimum of $50 \%$ of the façade area has to be reserved for windows. When the sky type is considered "clear" windows should account for at least $35 \%$ of the façade;

- Monthly values of air temperature to estimate if and in which seasons heating and cooling are required. For monthly temperatures below $10^{\circ} \mathrm{C}$ and above $23^{\circ} \mathrm{C}$ heating or cooling demand was assumed;

- Daily temperature changes, especially between day and night, to night ventilation to limit temperatures during the day. This works best, if a heavy construction is in place;

- Ground temperature to estimate the potential of geothermal systems;

- Relative humidity for estimating the potential of evaporative cooling;

- Wind velocity and direction for estimating the potential for natural ventilation.

\section{Results for international style and climate adapted scenario}

The investigations concerning the international style scenario based on the previously described assumptions (same energy system for the production of renewable energy for all locations) shows, that the level of primary energy demand is generally very high. This is a clear sign of the potential to optimize "international style" office buildings.

In order to cover the power demand for heat pump, artificial light and mechanical ventilation with PV modules (installed on the building's envelope), only a limited number of storeys is possible $(2,5$ in Hamburg and up to 4 in 
Mexico). Moreover, due to the high demand of thermal energy for heating and especially for cooling, a large estate is required to implement the geothermal system and distances between buildings reach values from around $30 \mathrm{~m}$ (Hamburg) to $70 \mathrm{~m}$ (Delhi). Therefore, in almost all of the locations, it is not possible to achieve the nearly-zero-energy standard based on the "international style" building in an urban context. In reality the results could be even worse. Many real buildings have different less efficient technical systems (e.g. a standard absorption chiller has a COP of about 1.5 ) with a higher primary energy demand, which has been excluded here, in order to compare just the architectural parameters.

Based on the climate analysis, best practice examples and vernacular architecture, specific architectural parameters (building depth, orientation, and window size) are modified according to local climate condition. For example building depth of only $10 \mathrm{~m}$ allows for better natural ventilation. The new energy demand, calculated for the optimized building, proved the remarkable reduction potential (see fig. 2). As a first step, the cases for the optimised scenarios are based on air-condition to ensure cooling. For all cases, it is assumed that no artificial light is used as soon as enough daylight is available.

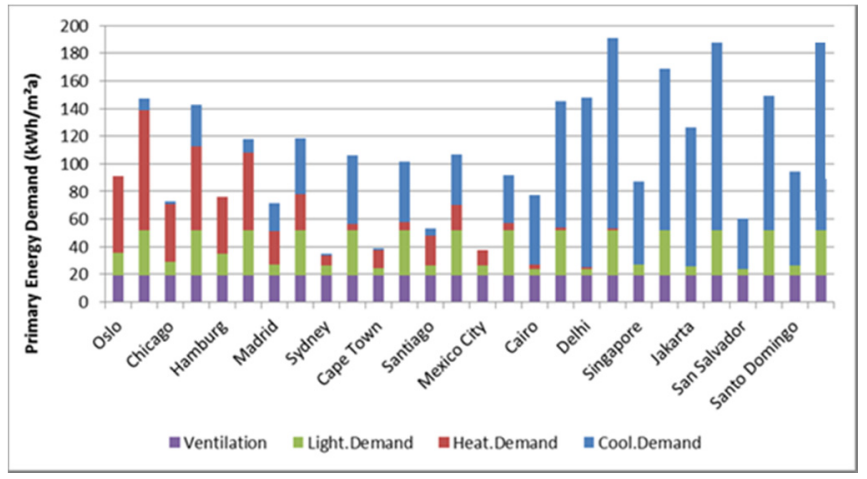

Figure 2: $\quad$ Primary energy demand of both scenarios for 14 locations.

For locations with cold winters, the optimized room has opaque façades with high thermal insulation, leading to a small reduction of heating demand. The power demand for artificial light has the biggest reduction in locations with a clear sky, receiving 12 hours of daylight in all months (e.g. near the equator, in Cairo or Delhi). Cooling demand can arise from high solar transmission through facades and a high outdoor temperature. To counteract, the solar transmission into buildings can be optimized with adequately sized window areas and efficient shading systems.

The highest reduction in energy demand can be found in locations where the cooling demand for an "international style" room arises from solar transmission (Santo Domingo, Singapore, Sydney). Inversely a high cooling demand remains for locations with high temperatures (Delhi, Jakarta) where the potential for optimization is limited. 
Even though the energy demand is reduced in this scenario, the possible number of storeys is limited according to the power supply (by PV through the building's envelope) to 3, 5 storeys the worst case (Jakarta) and 9 to 10 storeys are the maximum (Sydney, Mexico City).

The reduction of heating and cooling demand leads to a smaller geothermal system and thus less estate. Ensuring the energy supply of a nine-story building in Mexico City is possible by securing only $15 \mathrm{~m}$ distance between buildings. Nevertheless in hot and dry climates (Delhi) the required distance reaches over $100 \mathrm{~m}$.

\subsection{Adaptive and hybrid concepts}

Changings in environmental conditions throughout a year requires adaptation in of the building and its technical systems. An adaptive building is understood as a building where users can adapt their surrounding according to their preferences e.g. with operable windows, personal switches for artificial light, manageable mechanical ventilation, thermostats etc. In case users are able to adapt themselves to (eventually higher) indoor temperatures during hot periods by changing their clothes, they feel better in remarkably higher temperatures than in non-adaptive (air-conditioned) buildings [6]. Such a measure can be put in place for example by a weakened dress code or no regulations for clothing at all.

Adaptive comfort models such as (EN 15251, 2007) differ between naturally ventilated (adaptive) and air-conditioned (non-adaptive) buildings or hybrid concepts, using air conditioning in the hottest months and the natural ventilation in the remaining period. The EN 15251 model defines the acceptable indoor temperatures and relates them to the outdoor ambient temperature. While airconditioned buildings regularly cool down to a constant temperature (usually $26^{\circ} \mathrm{C}$ ), adaptive buildings vary the indoor temperature slightly with the mean value of the outdoor temperature. The use of "only" natural ventilation (very high air change) means that the indoor temperature is equal to outdoor temperature (light construction) or remains a few degrees below outdoor temperatures for heavy construction. Furthermore, an adaptive model as EN 15251 [7] allows for a specific percentage of hours ( 3 or $5 \%$ ), in which the indoor temperature can exceed.

As it becomes very clear in figure 3 , in climates such as Delhi, the percentage of hours exceeding the comfort level is much more than $3 \%$. Many points, indicating temperature, can be found above the upper comfort limit.

Nevertheless, it is noticed that exceeding hours consequently appear during the summer months. Thus, the comfort belt is not exceeded during a number of months and an adaptive mode is possible here. For such cases, a hybrid building is suggested, with 5 month of adaptive operation and 7 month with mechanical ventilation based on air conditioning.

People from hotter countries are more accustomed to higher temperatures. Their expected comfort temperature has been found to be as up to 4 degrees higher than the proposals made in EN 15251 [6]. This fact can be introduced in adaptive model as well, but should be discussed in detail with local people. 


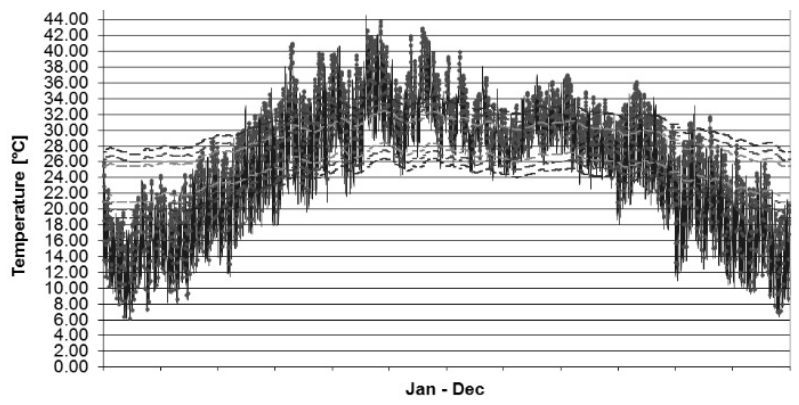

Figure 3: Comfort diagram temperature in Delhi according to EN 15251.

Adaptive building concepts are possible without any restriction in Oslo, Hamburg, Mexico City and Sydney during the whole year. If the upper line of the comfort belt is shifted upwards, adaptive building concepts according to EN 15251 can also be achieved in Singapore, Santiago de Chile (1 degree), Santo Domingo ( 2 degrees), Cairo and Jakarta (3 degrees). An important condition is that the users accept this upward shift.

\subsection{General conclusions from case study results}

The size of the geothermal system is determined by the peak values of the daily heating and cooling demand (not by the annual mean value). The biggest geothermal system is required in Delhi (hot and dry) for cooling and in Oslo for heating. Locations with high but not extreme temperatures (the hot and humid ones: Santo Domingo, San Salvador, Singapore, Jakarta) have a high annual cooling demand but they need a relatively small geothermal system to cover it. Moreover, vice versa, locations with shorter but extreme heat waves have a smaller annual cooling demand but they need a huge system to cover it.

Locations near the earth's poles (Oslo) have a very low solar supply, especially during the heating period. As a result, they also have a high demand of artificial light (darkness during time of use). Also because of the low position of the sun in the sky, the use of PV is not sufficient. Consequently, other possibilities for the supply of renewable power or compensating measures have to be regarded. Fortunately, for the cases of Oslo, the national power generation is almost $100 \%$ renewable, due to hydropower.

The best situation exists in locations with moderate temperatures, with a high level of solar radiation (Mexico City, Sydney) and generally close to the sea or with a high elevation. With such frame conditions, nearly-zero-energy standard can be achieved in very dense urban structures. Nevertheless, Zero-energy urban buildings are not possible in all locations. This holds also true for European countries where the directive must be fulfilled.

\section{Prognosis method}

A simple method is developed to derive the energy demand from the climate data. This is only possible, if the architecture is adapted as much as possible to the 
climate and is determined by the outdoor temperature or the daylight. There is no direct link between climate data and energy demand in the "international style" scenario. The energy demand values refer to annual and daily heating and cooling demand as well as power demand $\left[\mathrm{kWh} / \mathrm{m}^{2} \mathrm{a}\right]$.

$$
\begin{gathered}
\mathrm{HDHy}=\Sigma(20-\mathrm{Te}) \text { if } \mathrm{Te}<16^{\circ} \mathrm{C} \\
\mathrm{CDHy}=\Sigma(\mathrm{Te}-26) \text { if } \mathrm{Te}>26^{\circ} \mathrm{C} \\
\mathrm{GRHy}=\Sigma(1) \quad \text { if Igl,hor }>200 \mathrm{~W} / \mathrm{m}^{2} .
\end{gathered}
$$

Equations (1) to (3) give the definitions for the climatic parameters. These include the global radiation hours. Furthermore, HDHd [Kh/d] and CDHd $[\mathrm{Kh} / \mathrm{d}]$ are the daily maximum values of heating and cooling degree hours. For cooling and artificial light, it is assumed that both are running only during the time when the building is used. Artificial light is assumed to be switched off, as soon as the global horizontal radiation reaches $200 \mathrm{~W} / \mathrm{m}^{2}$.

The correlations between the energy demand parameters and the five climatic parameters can be proven, using the regression equations: $\mathrm{Y}=\mathrm{A} * \mathrm{X}+\mathrm{B}$. The fit $\left(\mathrm{R}^{2}\right.$ value) of these regressions lies between $74 \%$ and $99 \%$; Figure 4 shows a typical example. Based on this regression line, all possible locations can be added (on the x-axis) easily with the appropriate climate data set and the forecasted energy demand can be taken from the y-axis. As more locations are added to the tool, as more exact the correlation becomes.

\subsection{Improvement of the prognosis method}

The climate zones in figure 4 can be identified grouped above or below the regression line. With a closer look, it becomes clear, that all hot and humid

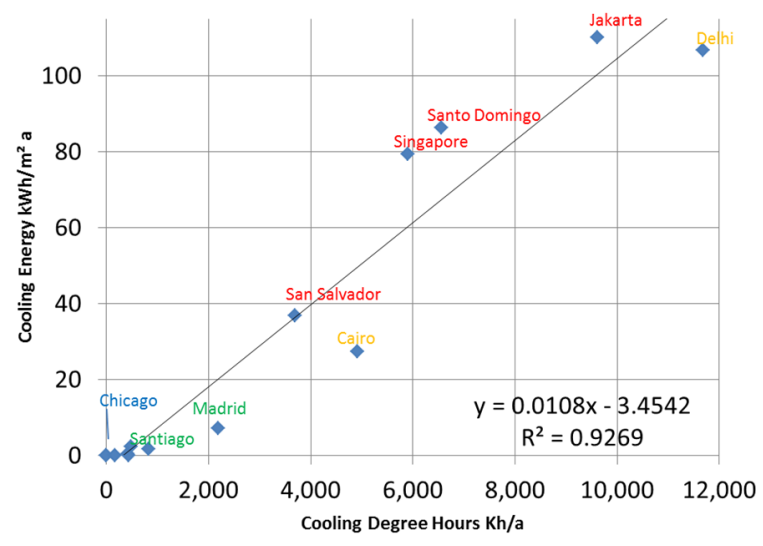

Figure 4: Correlation between annual cooling energy demand and CDHy, climate adapted optimised scenario. 
Table 1: Variables of regression equations.

\begin{tabular}{|l|l|l|l|}
\hline Y & A & X & B \\
\hline Yearly cooling energy demand $\left[\mathrm{kWh} / \mathrm{m}^{2} \mathrm{a}\right]$ & 0.0108 & CDHy & -3.4542 \\
\hline Yearly heating energy demand $\left[\mathrm{kWh} / \mathrm{m}^{2} \mathrm{a}\right]$ & 0.0005 & HDHy & -3.9752 \\
\hline Max. daily cooling energy demand $\left[\mathrm{Wh} / \mathrm{m}^{2} \mathrm{~d}\right]$ & 7.3567 & CDHd & -84.788 \\
\hline Max. daily heating energy demand $\left[\mathrm{Wh} / \mathrm{m}^{2} \mathrm{~d}\right]$ & 0.7691 & HDHd & -62.944 \\
\hline Power demand artificial light $\left[\mathrm{kWh} / \mathrm{m}^{2} \mathrm{a}\right]$ & 0.0106 & GRHy & -0.6389 \\
\hline
\end{tabular}

locations are above the regression line (cooling demand is higher than forecasted) and all the hot and dry ones are below (smaller cooling demand). The reason for this may be that in hot and dry climates, the combination of heavy construction and night ventilation with cool night air helps to reduce cooling demand. In hot and humid locations, this is very limited, leading to higher cooling demand. In order to improve the prognosis method further, the regression is carried out for three climate zones individually; for (A) equatorial climates; (B) arid climates; (C) warm temperate climates.

Table 2: Variables of regression equations in different climate zones.

\begin{tabular}{|l|l|l|l|}
\hline Y Yearly cooling energy demand $\left[\mathrm{kWh} / \mathrm{m}^{2} \mathrm{a}\right]$ & $\mathbf{A}$ & $\mathbf{X}$ & $\mathbf{B}$ \\
\hline "Hot and Humid" & 0,0120 & CDHy & 0,6873 \\
\hline "Hot and Dry" & 0,0117 & HDHy & $-30,0390$ \\
\hline "Temperate" & 0,0035 & CDHd & $-0,7851$ \\
\hline
\end{tabular}

The exemplary case of Jakarta is regarded in detail here. Comparing the actual simulated results for energy demand with both regression lines, the following improvement can be stated. While the first correlation including all 14 locations has a deviation of $10 \mathrm{kWh} / \mathrm{m}^{2}$ a downwards, the second correlation for the specific climate zone only differs by $5 \mathrm{kWh} / \mathrm{m}^{2} \mathrm{a}$, but upwards. Thus, a detailed look into the climate specific correlations helps to determine results that are more accurate. On the other hand, a correlation including all 14 locations prevents mistakes in the application of design rules by averaging. 


\section{Final results}

With only 14 locations, the database is relatively weak and requires expansion. As the rooms have just been optimized theoretically in student projects, there is no practical evidence. Therefore, further detailed investigations can help to steadily improve the prognosis tool to become more accurate. On the other hand, the correlations are surprisingly good and plausible. Results are in accordance with real ZEBs or zero-energy urban solutions.

This method can help taking design decisions in the early design stages without complex simulation. Applying the method, it can be easily said, if a ZEB is possible in a specific location. Furthermore an approximate forecast for the maximum number of storeys and the street width can be made (considering the mentioned assumptions and applied climate-responsive design rules). This may help architects, taking far-reaching design decisions already in an early design stage.

\section{Nomenclature}

HDHy = yearly heating degree hours $[\mathrm{Kh} / \mathrm{a}]$.

$\mathrm{CDHy}=$ yearly cooling degree hours $[\mathrm{Kh} / \mathrm{a}]$.

GRHy = yearly global radiation hours $[\mathrm{h} / \mathrm{a}]$.

Igl,hor $=$ global horizontal radiation $\left[\mathrm{W} / \mathrm{m}^{2}\right]$.

$\mathrm{Te} \quad=$ hourly outdoor temperature $\left[{ }^{\circ} \mathrm{C}\right]$.

\section{References}

[1] EPBD 2010, Energy Performance of Buildings Directive, http://www.epbdca.eu/, accessed March 2014

[2] Meteonorm 2010, Meteotest, Meteonorm Handbook part II: Theory, Version.6.120, April 2010

[3] Köppen, W. P. and Geiger R., Vetmeduni Vienna, http://koeppen-geiger.vuwien.ac.at/, accessed December 2013

[4] Zimmermann, M., Handbuch der passiven Kühlung, Rationelle Energienutzung in Gebäuden, 1999

[5] Climate Consultant 2012, http://www.energy-design-tools.aud.ucla.edu/, accessed December 2012

[6] Keonil, N. and Sahachaisaeree, N., Energy-efficient management modelling towards interior thermal comfort: A case of composite dwellings features manipulation in Bangkok, PLEA, p. 211, 2011

[7] EN 15251, Indoor environmental input parameters for design and assessment of energy performance of buildings addressing indoor air quality, thermal environment, lighting and acoustics, 2007 